\title{
T-regulatory cells from patients with rheumatoid arthritis retain suppressor functions in vitro
}

\author{
DANIIL SHEVYREV ${ }^{1}$, VALERIY TERESHCHENKO ${ }^{2}$, VLADIMIR KOZLOV ${ }^{1}$, \\ ALEXEY SIZIKOV $^{3}$, OKSANA CHUMASOVA ${ }^{3}$ and VERONICA KOKSHAROVA ${ }^{3}$ \\ Laboratories of ${ }^{1}$ Clinical Immunopathology and ${ }^{2}$ Molecular Immunology; \\ ${ }^{3}$ Rheumatology Department, Federal State Budgetary Scientific Institution, Research Institute \\ of Fundamental and Clinical Immunology, Novosibirsk 630099, Russia
}

Received January 11, 2020; Accepted July 27, 2020

DOI: $10.3892 / \mathrm{etm} .2021 .9641$

\begin{abstract}
Rheumatoid arthritis (RA) is a chronic disease of connective tissue caused by intolerance to self-antigens. Regulatory $\mathrm{T}$ cells (Tregs) are key players in maintaining autotolerance through a variety of suppressor mechanisms. RA is generally believed to develop due to disorders in Tregs; however, there is no consensus on this issue. Thus, the present study focused on phenotypical analysis of Treg cells and their ability to suppress $\mathrm{CD}^{+}$and $\mathrm{CD}^{+}$cell proliferation. The present study used peripheral blood samples from 21 patients with RA and 22 healthy donors. The $\mathrm{CD} 25^{+} \mathrm{FoxP} 3^{+}$subpopulation of Tregs was analyzed using flow cytometry to evaluate the expression of CTLA-4, PD-L1, HLA-DR, CCR4, CD86 and RORyt. Tregs suppressor activity was calculated in terms of suppression of the proliferation of $\mathrm{CD}^{+}$and $\mathrm{CD}^{+}$lymphocytes in vitro. Suppressor activity of the total Treg population did not differ between patients with RA and healthy donors. However, the patients had elevated CD $25^{\text {lo }}$ FoxP $3^{+}$levels and lower $\mathrm{CD} 25^{\text {hi }}$ FoxP3 ${ }^{+}$levels; in addition, they had more activated Tregs expressing PD-L1, HLA-DR, CCR4 and CD86. The surface expression of CTLA-4 was below the reference level. The patients also had transitional FoxP $3{ }^{+} \mathrm{RORyt}^{+}$cells and elevated $\mathrm{CD} 4^{+} \mathrm{RORyt}^{+}$levels, which were highly correlated with disease activity. These results show that in RA, Treg cells are activated and have an immunosuppressive activity. However, it is the transitional FoxP $3^{+} \mathrm{RORyt}^{+}$cells and increased $\mathrm{CD}^{+}{ }^{+} \mathrm{RORyt}^{+}$percentages in peripheral blood that appear to be associated with the pathological conversion of some Treg cells into Th-17. This process appears to be key in RA pathogenesis.
\end{abstract}

Correspondence to: Dr Daniil Shevyrev, Laboratory of Clinical Immunopathology, Federal State Budgetary Scientific Institution, Research Institute of Fundamental and Clinical Immunology, 15 Yadrintsevskaya Street, Novosibirsk 630099, Russia E-mail: dr.daniil25@mail.ru

Key words: regulatory $\mathrm{T}$ cells, rheumatoid arthritis, suppressor activity, RORyt ${ }^{+}$lymphocytes

\section{Introduction}

Rheumatoid arthritis (RA) is a chronic autoimmune disease that primarily affects joints and other organ systems, often disabling the patient (1). RA pathogenesis lies in the excessive and continuous activation of effector cells by self-antigens, which causes progressive inflammation and damages tissues and organs (2). Regulatory T cells (Tregs) are primary immunosuppressive cells that keep immunity balanced and maintain tolerance to self-antigens (3). It is assumed that dysfunction of these cells contributes to RA pathogenesis (4). The quantitative data currently available on Treg populations in RA are contradictory, due to a high level of heterogeneity in disease duration and therapy approaches in patients with RA (5-7). There is no consensus on the suppressor activity of Treg cells in RA either, which may be due to research on the topic being limited (8-11). The present study sought to analyze the Treg subpopulation and functional activity in RA.

Treg cells provide a broad range of regulatory mechanisms by contact or humoral interactions (3). For that reason, the present study investigated not only their ability to suppress the proliferation of responder cells, but also the expression of CTLA-4 and PD-L1 molecules involved in contact suppression. The Treg ability to produce regulatory cytokines, TGF- $\beta$ and IL-10, was also studied. In addition, the researchers studied the Treg migration potential via CCR4 expression (12) and the extent of their activation by HLA-DR expression $(13,14)$. Given that T-cell receptors (TCRs) are involved in the trans-endocytosis of CD80/86 molecules with CTLA-4 involvement (15), to the best of our knowledge, the present study was the first to propose using CD86 molecules as a marker of the Treg/antigen presenting cell (APC) interaction intensity, which may be representative of the contact suppressor activity of Treg cells against a specific range of antigens.

An increasing amount of data is available on the negative effects of converting Treg cells in RA-associated inflammation, including decreasing FoxP3 expression and triggering the expression of the RORyt transcription factor to Th17 cells. For example, exFoxP3 lymphocytes have stronger osteoclastogenic potential compared with that in Th17 originating from Th0; they are less susceptible to Treg suppression $(16,17)$. In addition, exFoxP3-Th17 lymphocytes play a key role in 
the inflammation and articular damage in RA, due to the intense production of inflammatory cytokines, IL-17, IL-21 and IL-22 (18). To effectively assess the Treg subpopulation and their ability to differentiate to Th17 cells, the present study counted transitional FoxP3 ${ }^{+} \mathrm{RORyt}^{+}$lymphocytes and $\mathrm{CD}^{+}{ }^{+} \mathrm{RORyt}^{+}$lymphocytes in the peripheral blood of RA patients compared with that in the donor group. As RORyt is the main transcriptional factor of Th17 cells, then bi-positive FoxP $3{ }^{+} \mathrm{RORyt}^{+}$and $\mathrm{CD} 4{ }^{+} \mathrm{RORyt}^{+}$lymphocytes may have potential for IL-17 expression (19), and might be involved in RA pathogenesis. Thus, the present study evaluated Treg cells in terms of their suppressor potential, the extent of activation and the degree of differentiation into pathogenic exFoxP3-Th17 lymphocytes.

\section{Materials and methods}

Patients. The present study used peripheral blood samples from 22 conditionally healthy donors (controls) and 21 patients affected by oligo- or polyarticular RA, with low, moderate and high disease activity (20); the duration of disease was $7.1 \pm 4.1$ years on average. Disease activity was evaluated by the Disease Activity Score (DAS)-28 criterion (21), which is an indicator that takes into account erythrocyte sedimentation rate (ESR) and number of inflamed or painful joints, as well as a subjective assessment of the patient's state of health through a patient global assessment based on patient reported outcomes (22). Additionally, ESR, level of C-reactive Protein (CRP), and level of rheumatoid factor (RF) were evaluated in the laboratory. Blood was sampled in cases of manifestation of RA or exacerbation upon hospitalization of each patient to the immunopathology unit. The general patient group according to disease duration included: Patients with new-onset RA [disease-modifying anti-rheumatic drugs (DMARD)-naïve] 7 persons; and patients on DMARD therapy, 14 persons. DMARDs included basic commonly accepted treatments, methotrexate and glucocorticoids. Donor and patient groups were comparable in sex and age; the donors were aged $52 \pm 11$ years; the patients were aged $51 \pm 16$ years (Table I). RA was diagnosed following the 1987 American College of Rheumatology criteria (23).

Patients were recruited between November 2018 and December 2019 at the Clinic of Immunopathology of the Research Institute of Fundamental and Clinical Immunology (RIFCI; Novosibirsk, Russia).

The exclusion criteria were as follows: i) Pregnancy or lactation; ii) an acute infection; iii) any vaccination within 3 months prior to the study; iv) any severe infection or somatic pathology; an v) the use of any of genetically engineered biological drugs. In all cases, blood was sampled upon written voluntary informed consent and the local Ethics Committee's Approval (protocol no. 110: October 11, 2018; RIFCI Ethics Committee).

Flow cytometry. Peripheral blood mononuclear cells (PBMCs) were obtained via Ficoll-Urografin $(\rho=1,077 \mathrm{~g} / 1)$ density gradient centrifugation (Ficoll ${ }^{\circledR}$ was supplied by Biolot; cat. 1.2.8.1., Urografin was supplied by Bayer AG), at 1,153 $\mathrm{RCF}$ for $25 \mathrm{~min}$ at room temperature $(24,25)$. Phenotypic traits of Treg-cells $\left(\mathrm{CD}^{+} \mathrm{CD}^{+}{ }^{+} \mathrm{CD} 25^{+} \mathrm{FoxP} 3^{+}\right)$from the PBMCs were tested using monoclonal antibodies: CD3 using FITC (cat. no. 300406), CD4 using APC/Cy7 (cat. no. 300518), CD25 using APC (cat. no. 302610), FoxP3 using PE (cat. no. 320108), CTLA-4 using PE/Cy7 (cat. no. 349914), PD-L1 using PE/Cy7 (cat. no. 329718), HLA-DR using PerCP (cat. no. 307628), CD86 using PE/Cy7 (cat. no. 305422), and CCR4 using PE/Cy7 (cat. no. 335405), which were all supplied by BioLegend, Inc. These antibodies were used at a volume of $5 \mu 1$ per $10^{6}$ cells. Cells were stained for RORyt using PerCP (R\&D Systems, Inc.; cat. no. IC6006C; $10 \mu \mathrm{l}$ per $10^{6}$ cells). For intracellular staining, the present study used a True-Nuclear Transcription Factor Buffer Set according to the manufacturer's instructions (BioLegend, Inc.; cat. no. 424401). CTLA-4 expression analysis estimated the surface and total (membrane + intracellular) expression of this molecule. When studying the phenotypical traits of Treg-cells while experimentally suppressing the proliferation of responder $\mathrm{T}$ cells, intracellular markers were not used as the cultures were not rich in these cells. The phenotype $\left(\mathrm{CD} 3{ }^{+} \mathrm{CD} 4^{+} \mathrm{CD} 25^{+} \mathrm{CD} 127^{\text {lo }}\right)$ was evaluated using the following monoclonal antibodies: $\mathrm{CD} 3$ using $\mathrm{PE} / \mathrm{Cy} 7$ (cat. no. 300420), CD4 using APC/Cy7 (cat. no. 300518), CD25 using PE (cat. no. 302606), CD127 using PerCP/Cy5.5 (cat. no. 351322), CTLA-4 using APC (cat. no. 349908), and PD-L1 using APC (cat. no. 329708), which were all supplied by BioLegend, Inc., at a volume of $5 \mu 1$ per $10^{6}$ cells. To assess the positive population when testing the expression of the studied molecules, the team applied fluorescence minus one controls, as well as isotype controls to assess the expression of RORyt. Additionally, the percentage of subpopulations of Treg cells with low and high CD25 expression was evaluated $\left(\mathrm{CD} 25^{\text {lo }} \mathrm{FoxP}^{+}\right.$and $\mathrm{CD} 25^{\text {hi }} \mathrm{FoxP}^{+}$respectively). Mean fluorescence intensity (MFI) was used for evaluation of expression density of CTLA-4 and PD-L1 on the Treg surface. Flow cytometry was performed on the BD FACS Canto II cytometer (BD Biosciences).

Treg suppressor activity. Treg functional activity was investigated by evaluating the suppression of $\mathrm{CD}^{+}$and $\mathrm{CD}^{+}$ proliferation in vitro upon stimulation. A pure Treg population was extracted using immunomagnetic separation from PBMCs by the Miltenyi Biotec Ltd. MACS Treg Isolation kit; the population was isolated to have a $\mathrm{CD} 3{ }^{+} \mathrm{CD} 4{ }^{+} \mathrm{CD} 25^{+} \mathrm{CD} 127^{\text {low }}$ phenotype. The purity of magnetic sorting was $93.2 \pm 4 \%$, on average. The Treg-depleted PBMC fraction was stained with a carboxyfluorescein succinimidyl ester (CFSE) vital stain (Invitrogen; Thermo Fisher Scientific, Inc.) following the manufacturer's instructions. Then, Treg cells were cultured with PBMCs, at a 1:1 ratio (30,000 Treg per 30,000 PBMC) over 4 days, in round-bottomed plates with RPMI-1640 medium (Sigma-Aldrich; Merck KGaA), supplemented with 10\% FCS (HyClone; Cytiva) and antibiotics at $37^{\circ} \mathrm{C}$ and $5 \% \mathrm{CO}_{2}$. IL-2 (25 U/ml (BIOTECH, Ltd.) coupled with anti-CD3 antibodies $(0.25 \mu \mathrm{g} / \mathrm{ml})$ (Sorbent), were used as proliferation stimulants. The cells were also cultured without stimulants as controls. CFSE-labeled PBMCs were cultured under the same conditions without Treg cells. Supernatants were sampled on day 3 to determine ELISA for IL-10 (Vector-Best) and TGF $\beta$ (BioLegend, Inc.) concentrations as these are the main Treg suppressor cytokines. CTLA-4 and PD-L1 expression on Treg cells was calculated on day 4; the Treg suppression index 
Table I. Clinical parameters of patients with RA and healthy donors.

Patients with RA

\begin{tabular}{lccc} 
Parameter & Healthy donors & Receiving DMARD therapy & New-onset \\
\hline Sex & 11 & 5 & 2 \\
Male & 11 & 9 & 5 \\
Female & $52 \pm 11$ & $55 \pm 13$ & $45 \pm 14$ \\
Mean age $\pm \mathrm{SD}$, years & - & $17.4 \pm 12.7$ & $22.8 \pm 14.2$ \\
Mean CRP $\pm \mathrm{SD}, \mathrm{mg} / \mathrm{dl}$ & - & $34.8 \pm 13.4$ & $32.29 \pm 14.2$ \\
Mean ESR $\pm \mathrm{SD}, \mathrm{mm} / \mathrm{h}$ & - & $372.7 \pm 216.1$ & $386.7 \pm 219.1$ \\
Mean RF $\pm \mathrm{SD}, \mathrm{IU} / \mathrm{ml}$ & - & $3.6 \pm 2.1$ & $3.9 \pm 2.4$ \\
Mean DAS-28 $\pm \mathrm{SD}$ & - & $6.2 \pm 4.5$ years & $<2$ weeks \\
Duration of treatment & $\mathrm{a}$ & & \\
\hline
\end{tabular}

No significant differences were found in CRP, ESR, RF or DAS-28 between patients with new-onset RA and those receiving DMARD therapy. aPresented as mean \pm SD for RA patients with DMARD therapy (years) and number of weeks for patients with new-onset RA. RA, rheumatoid arthritis; DMARD, disease-modifying anti-rheumatic drugs; CRP, C-reactive protein; ESR, erythrocyte sedimentation rate; RF, rheumatoid factor.

was calculated for $\mathrm{CD}^{+}$and $\mathrm{CD}^{+}$cells using the following formula (26):

$$
I=100 \times\left(1-\frac{\text { percentage of dividing lymphocytes }+ \text { Treg }}{\text { percentage of dividing lymphocytes, no Treg }}\right)
$$

Statistical analysis. The data was analyzed using Statistica v6.0 (TIBCO Software, Inc.) and two non-parametric methods, the Wilcoxon test for dependent samples and the Mann-Whitney test for independent samples, and one parametric method, a two-tailed Student's t-test. For multiple independent groups ( $>2)$, ANOVA was used (the Kruskal-Wallis test in case of non-parametric distribution), followed by post hoc analysis (Tukey's and Dunn's multiple comparison tests for parametric and non-parametric distribution, respectively). The Shapiro-Wilk test was used for investigating normality distribution. For correlation analysis, the Spearman's rank correlation test was used. $\mathrm{P}<0.05$ was considered to indicate a statistically significant difference. Non-parametric methods were used for descriptive statistics in cases of non-parametric distribution: The median and interquartile ranges were calculated at 25 and $75 \%$ percentiles. Parametric methods were used for descriptive statistics in cases of Gaussian distribution: Mean \pm SD. Graphs were generated using GraphPad Prism (v7.03; GraphPad Software, Inc.).

\section{Results}

Peripheral blood Treg subpopulations in RA. To analyze the population of Treg cells in peripheral blood, the total $\mathrm{CD} 25^{+} \mathrm{FoxP} 3^{+}$pool was calculated as a percentage, as were the subpopulations with low and high CD25 expression: CD25 $5^{\text {lo }}$ and $\mathrm{CD} 25^{\text {hi }}$, respectively (Fig. 1A).

The percentage of $\mathrm{CD} 25^{+} \mathrm{FoxP} 3^{+}$Treg lymphocytes did not significantly differ from that in RA patients in either the new-onset RA or DMRAD therapy groups (data not shown). However, patients in both groups had significantly more $\mathrm{CD} 25^{\text {lo }} \mathrm{FoxP} 3^{+}$Tregs and significantly fewer CD25 ${ }^{\text {hi FoxP3 }}{ }^{+}$Tregs (Fig. 1B; data shown for donors and the general group of RA patients).

In addition, receiver operating characteristics (ROC) curves were plotted for the Treg percentage (Fig. 2). The area under the ROC curve, of the Treg percentage for the RA prediction was 0.68 , showing its low predictive ability $(\mathrm{P}=0.03)$. This confirmed the absence of a significant difference between donors and RA patients in the percentage of Tregs.

The IL-2R/Jak/STAT5 pathway is important to the stable expression of FoxP3 (27), which might be disrupted by RA-related inflammation, due to the effects of IL-6 and TGF- $\beta$ (17), in which case the RORyt transcription factor is expressed and Treg cells differentiate into exFoxP3-Th17 lymphocytes (28). Thus, a lower expression of CD25 (IL-2R) might be associated with the conversion of Treg cells to Th17. As a result, the expression of RORyt using $\mathrm{CD} 4^{+}$lymphocytes in the blood samples from donors and patients with RA, as a marker of early differentiation to Th17 lymphocytes.

Fig. 3A shows the examples of the flow cytometry plots reflecting the gating of the $\mathrm{CD}^{+}{ }^{+} \mathrm{RORyt}^{+}$and FoxP3 ${ }^{+} \mathrm{RORyt}^{+}$ cells. Patients with medium and high disease activity had significantly more RORyt-expressing cells compared with that in the healthy donors and patients with low activity, both in $\mathrm{CD}^{+}$cells and in $\mathrm{CD}^{2} 5^{+}$FoxP3 ${ }^{+}$Treg cells (Fig. 3B and C). At the same time, FoxP3 ${ }^{+} \mathrm{RORyt}^{+}$had relatively low CD25 expression (data not shown).

RORyt is the main transcription factor for Th17 lymphocytes; therefore, Fox P $3{ }^{+} \mathrm{RORyt}^{+}$cells are the Treg-to-Th17 transition stage (29). Thus, Treg cells in the patients were more prone to differentiate into Th17 (29). Furthermore, a strong correlation was found between the percentage of $\mathrm{CD}^{+}{ }^{+} \mathrm{RORyt}{ }^{+}$cells and DAS-28, and between the percentage of FoxP $3{ }^{+} \mathrm{RORyt}^{+}$cells and DAS-28, which suggested that the process of transdifferentiation from Treg to Th17 could be involved in the pathogenesis of RA (Fig. 4A and B; RA patients from the general group). 


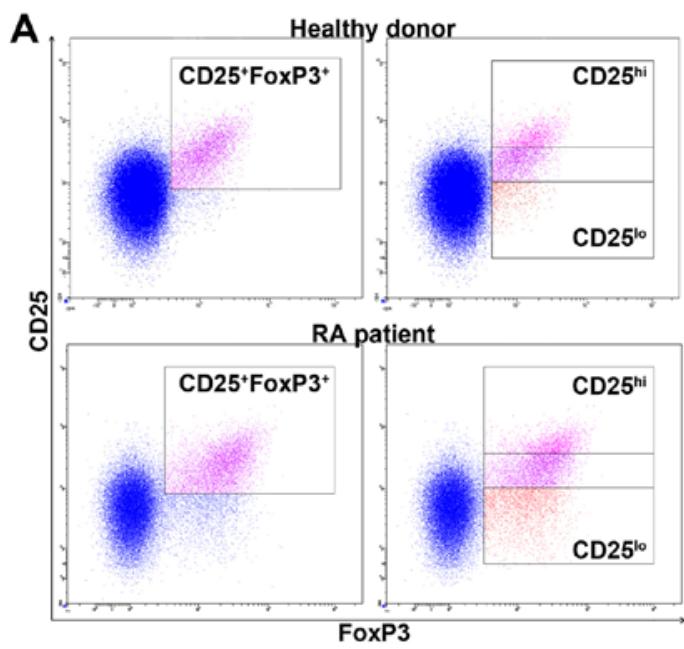

B

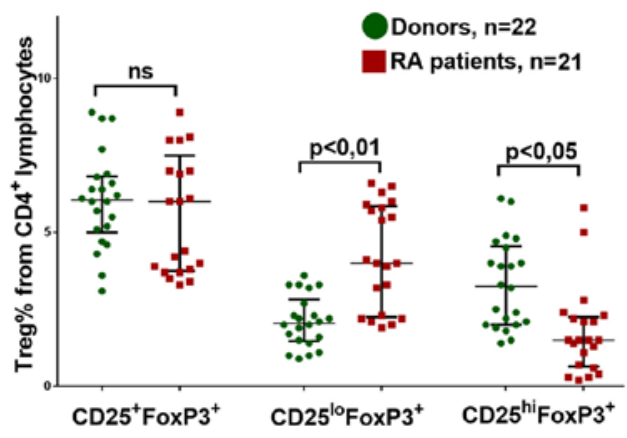

Figure 1. Peripheral blood Treg subpopulations in RA. (A) Gating of the total Treg population and low and high CD25 expression populations from the $\mathrm{CD} 3^{+} \mathrm{CD} 4^{+}$lymphocytes. Flow cytometry plots are representative of one healthy donor and one patient with RA. (B) Various Treg subpopulations in the peripheral blood from healthy donors and patients with RA. Healthy donors, $n=22$, RA patients, $n=21$. The data are presented as the median and $25-75 \%$ interquartile range. The Mann-Whitney test was used to analyze the data. Lo, low; hi, high; RA, rheumatoid arthritis; Treg, regulatory T cells; ns, not significant.

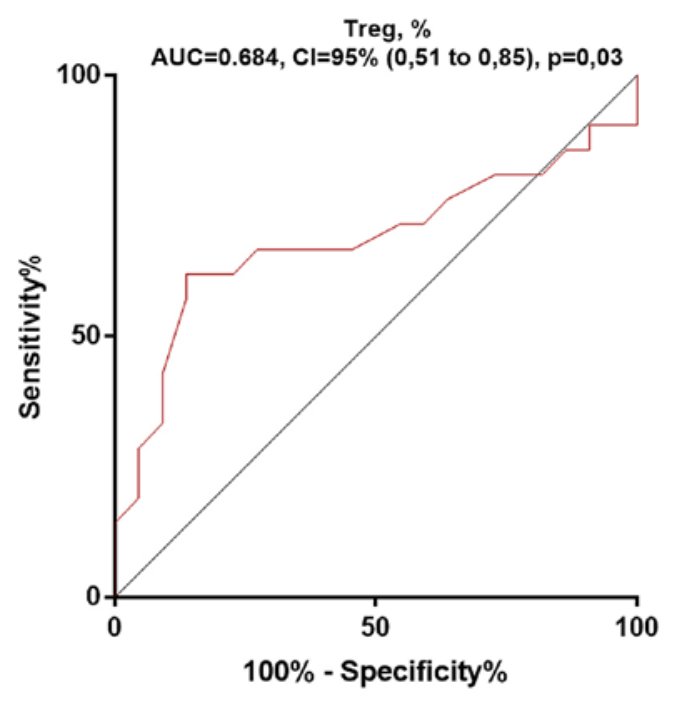

Figure 2. Absence of a significant difference between donors and RA patients in the percentage of Tregs receiver operating characteristics curve of the Treg cell frequencies for the RA prediction. Healthy donors, $n=22$, RA patients, $\mathrm{n}=21$. AUC, area under the curve; Treg, regulatory $\mathrm{T}$ cells; RA, rheumatoid arthritis.

Additionally, a strong correlation was found between the percentage of FoxP $3{ }^{+} \mathrm{RORyt}^{+}$and $\mathrm{CD}^{+}{ }^{+} \mathrm{RORyt}{ }^{+}$cells, which indicates transdifferentiation between Treg cells and Th-17 lymphocytes. (Fig. 4C; RA patients from the general group) (30).

Thus, it was revealed that features of Treg cells in patients with RA could contribute to the pathogenesis of the disease by promotion and maintenance of inflammation. It is important to note that some studies did not find IL-17 expression in different Treg cell subsets, while Th17 cells expressing IL-17 were present in the blood $(10,31)$. This may be due to the expression of RORyt being initiated at the early stage of Th17 cell differentiation and IL-17 being undetectable in the transient stage of FoxP3 ${ }^{+} \mathrm{RORyt}^{+}$cells (32).
Expression of functional molecules and activation molecules on Treg-cells in RA. For the following experiments, 12 donors and 12 patients with RA (DAS-28 >3.2) were randomly selected from the general group, who were comparable by sex and age, and the expression of CD86, CTLA-4, PD-L1, HLA-DR and CCR4 (the gating strategy is shown in Fig. 5), which are involved in the functional activity of Treg cells (14), was investigated. A total of 6 patients had new-onset RA and six were receiving DMARD therapy. However, no significant differences were found between these RA groups using expression density (MFI) of these molecules or the percentage of Treg cells, as determined by the positive expression of CD86, CTLA-4, PD-L1, HLA-DR and CCR4 (Fig. 6A). Notably, with the patients with $\mathrm{RA}$ receiving DMARD therapy, the percentage of CCR4 ${ }^{+}$Treg cells was slightly higher compared with that in the patients with new-onset RA. This may be due to the different average durations of the disease in these groups (6.2 \pm 4.5 years and $<2$ weeks respectively).

Some differences were also found between donors and patients with RA from the common group. Investigating CD86 expression on the surface of Treg, it was found that in patients with RA, the percentage of $\mathrm{CD} 86^{+} \mathrm{CD} 25^{+} \mathrm{FoxP} 3^{+}$cells was significantly higher (Fig. 6B).

The percentage of Treg cells with surface CTLA-4 expression was significantly lower in the all patients with RA compared with that in the healthy donors (Fig. 6B). The mean fluorescence, which is indicative of the CTLA-4 expression density on cell surface, was also significantly lower for the general patient group (data not shown). However, at the same time, neither donors nor patients differed significantly, with respect to total (surficial + intracellular) CTLA-4 expression: 94.5 (range, 94-98\%) vs. 96.8\% (range, 97-98\%), respectively (data not shown). This may be explained by the higher intensity of internalization of the CTLA-4 molecule, in complex with CD86, in patients with RA, and by the exhaustion of the CTLA-4 mediated mechanism of Treg-suppression (15).

Patients with RA also had significantly more PD-L1-expressing Treg cells in peripheral blood (Fig. 6B). This 


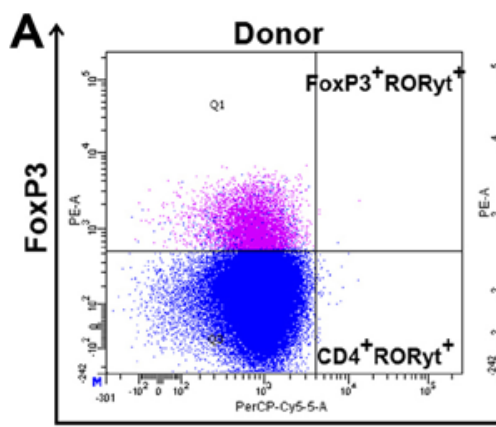

RA patient, DAS28<3,2

RA patient, DAS28 $>3,2$
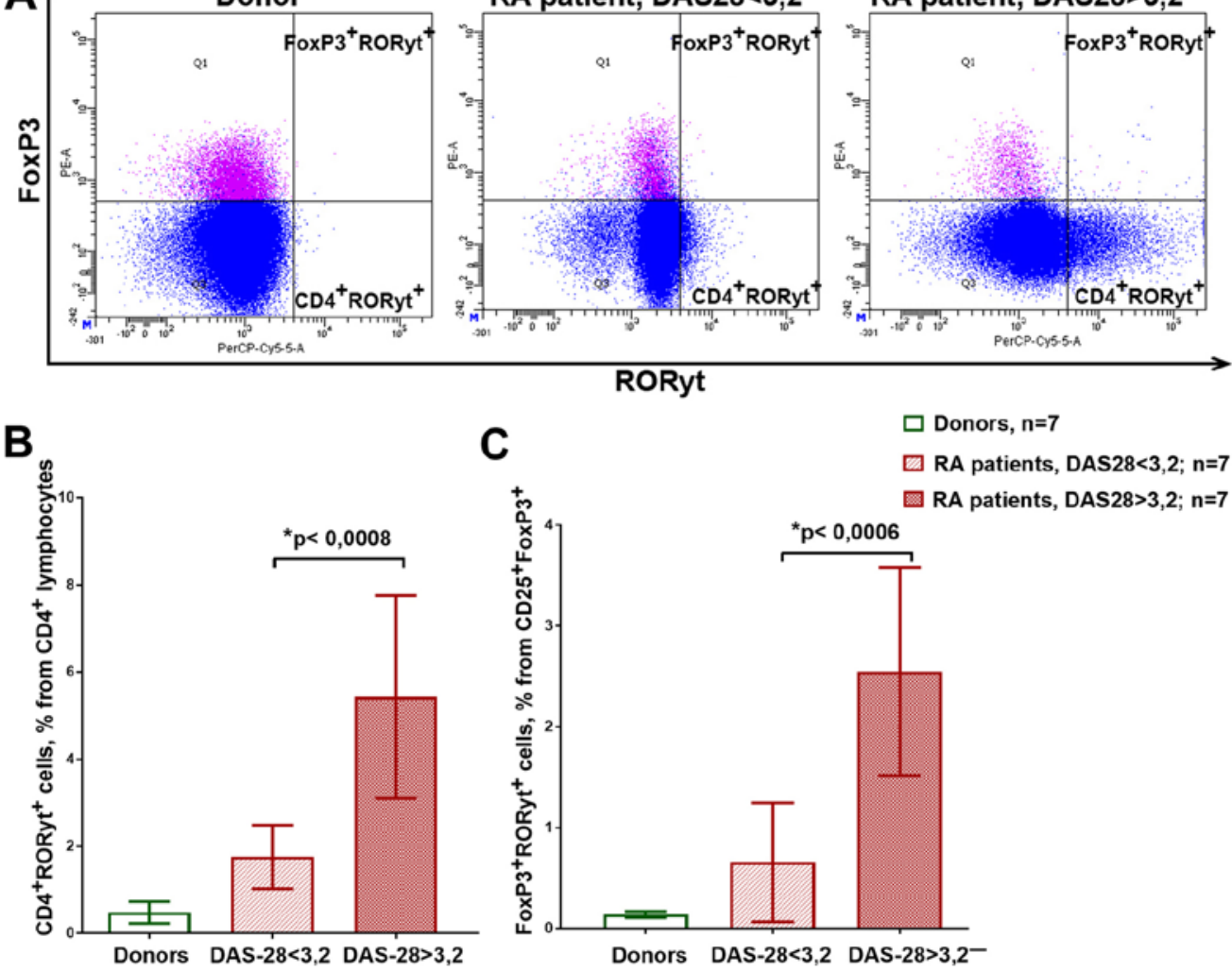

RORyt

C

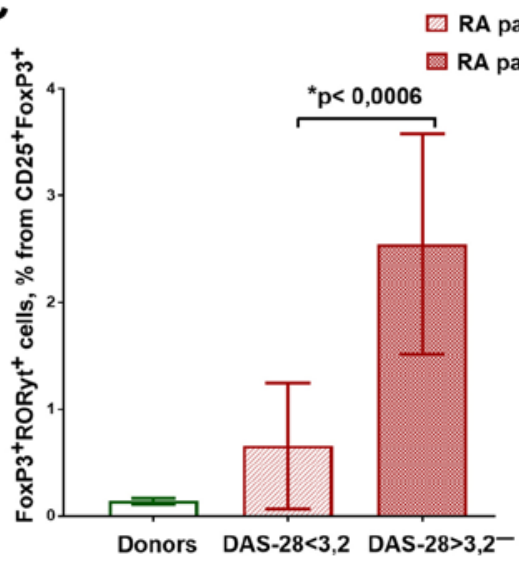

Figure 3. Flow cytometry plots reflecting the gating of the CD4 ${ }^{+} \mathrm{RORyt}^{+}$and FoxP $3^{+} \mathrm{RORyt}^{+}$cells. (A) Representative flow cytometry plots of $\mathrm{CD} 4^{+} \mathrm{RORyt} \mathrm{t}^{+}$ and FoxP3 ${ }^{+} \mathrm{RORyt}^{+}$lymphocytes from one donor and two patients, with an index of DAS-28, <3.2 and $>3.2$. (B) RORyt expression in the peripheral blood from $\mathrm{CD}^{+}{ }^{+}$lymphocytes. (C) Percentage of FoxP3 ${ }^{+}$RORyt $^{+}$lymphocytes from peripheral blood. Healthy donors, $\mathrm{n}=7$, RA patients with DAS-28<3.2, $\mathrm{n}=7$, RA patients with DAS-28>3.2, $\mathrm{n}=7$. The data are presented as the mean \pm SD and compared using one-way ANOVA and Tukey's post hoc test. RA, rheumatoid arthritis; DAS-28, Disease Activity Score-28.
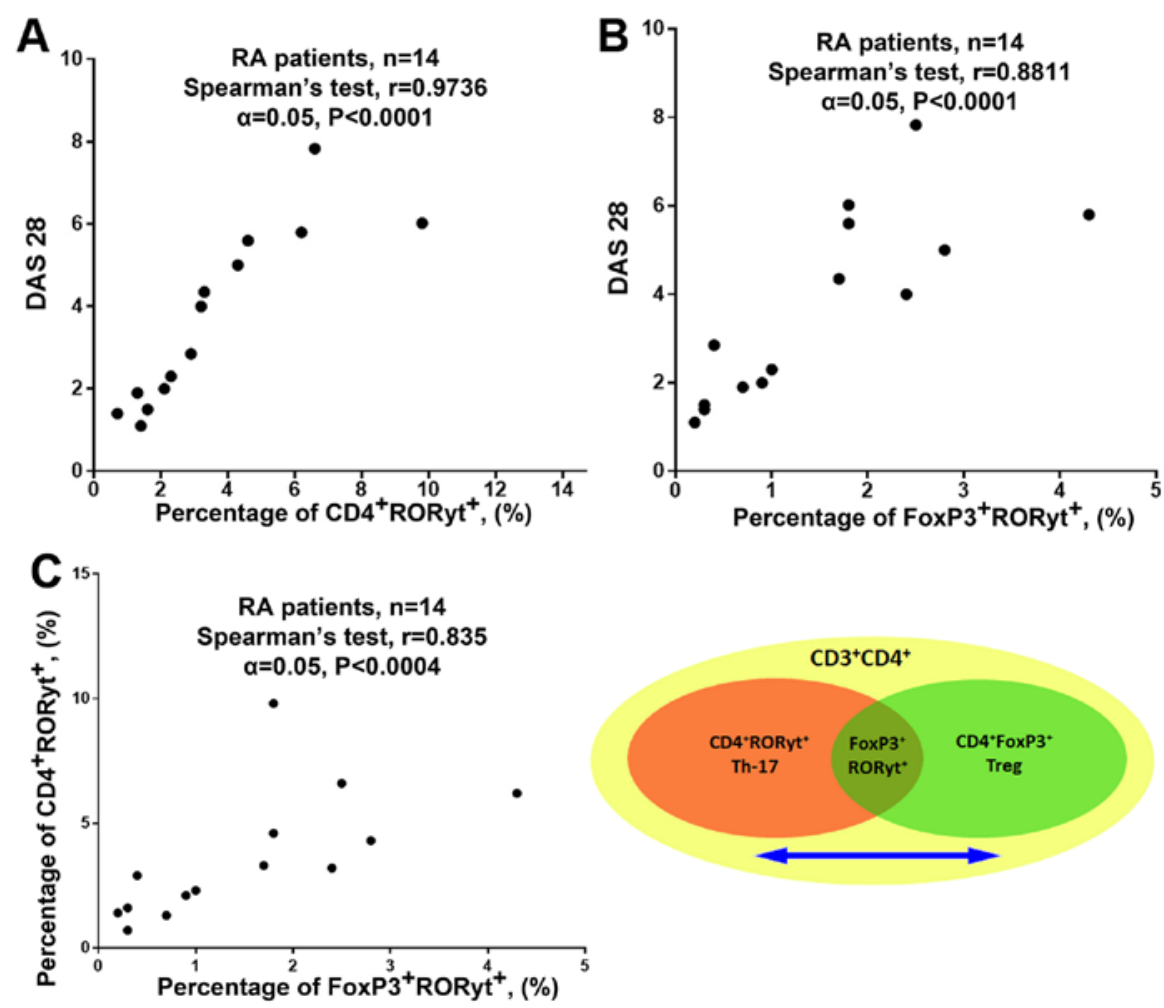

Figure 4. Correlation analysis suggests transdifferentiation from Treg to Th17. Correlation between blood (A) CD4 $4^{+} \mathrm{RORyt}^{+}$and (B) FoxP $3^{+} \mathrm{RORyt}^{+}$lymphocyte count and disease activity using DAS-28, (C) correlation between $\mathrm{CD} 4{ }^{+} \mathrm{RORyt}^{+}$and FoxP3 ${ }^{+} \mathrm{RORyt}^{+}$lymphocyte count. RA patients, $\mathrm{n}=7$ (for each chart). RA, rheumatoid arthritis. 

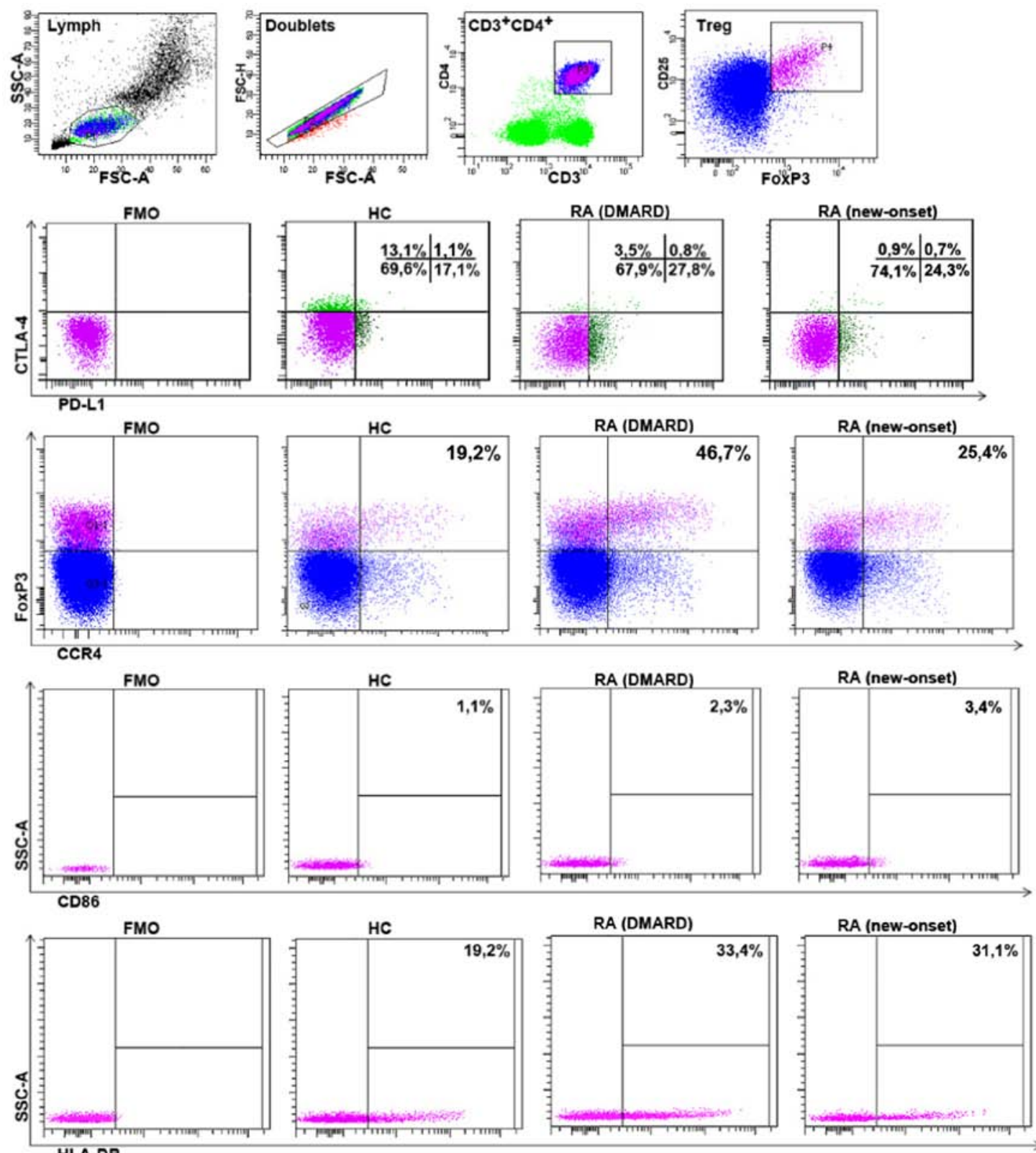

Figure 5.The gating strategy for the evaluation of CD86, CTLA-4, PD-L1, HLA-DR and CCR4 expression from Treg cells. Treg, regulatory T cells; HC, healthy controls; DMARD, disease-modifying anti-rheumatic drugs; RA, rheumatoid arthritis; FMO, fluorescence minus one.
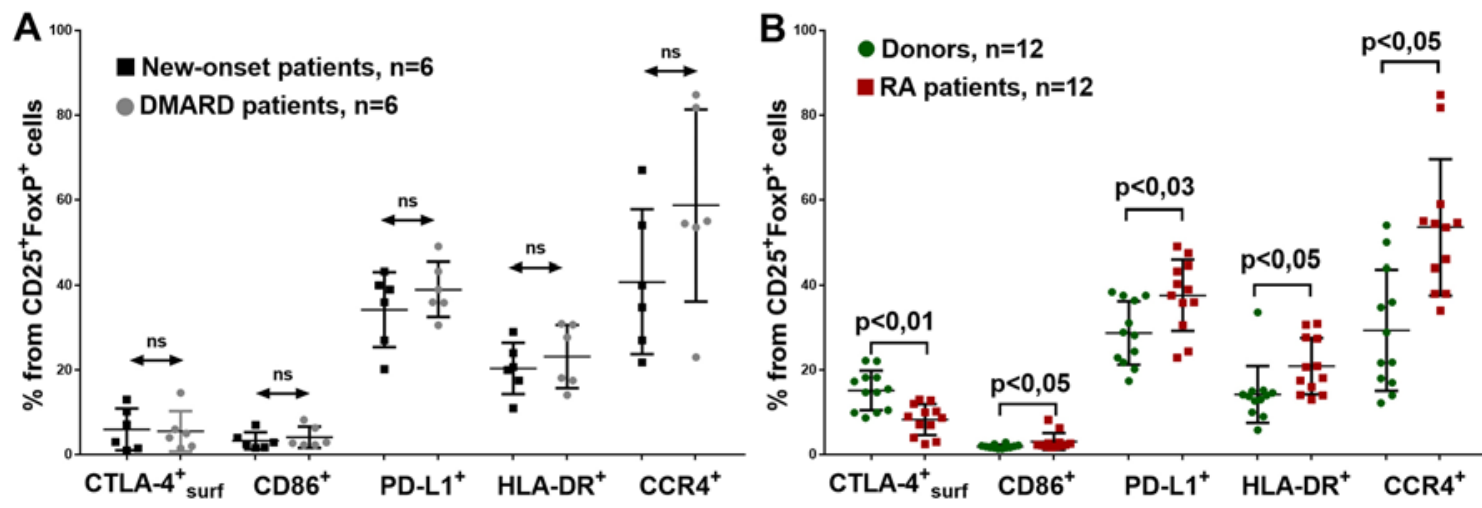

Figure 6. Expression of functional molecules on Treg-cells in RA. Expression of functional Treg markers in the peripheral blood in (A) patients with new-onset $\mathrm{RA}(\mathrm{n}=6)$ and those receiving DMARD $(\mathrm{n}=6)$ and in $(\mathrm{B})$ donors $(\mathrm{n}=12)$ and patients with $\mathrm{RA}(\mathrm{n}=12)$. The data are presented as the median and $25-75 \%$ interquartile range and was analyzed using the Mann-Whitney test. RA, rheumatoid arthritis; Treg, regulatory T cells; surf, surface; DMARD, disease-modifying anti-rheumatic drugs; ns, not significant. 
A

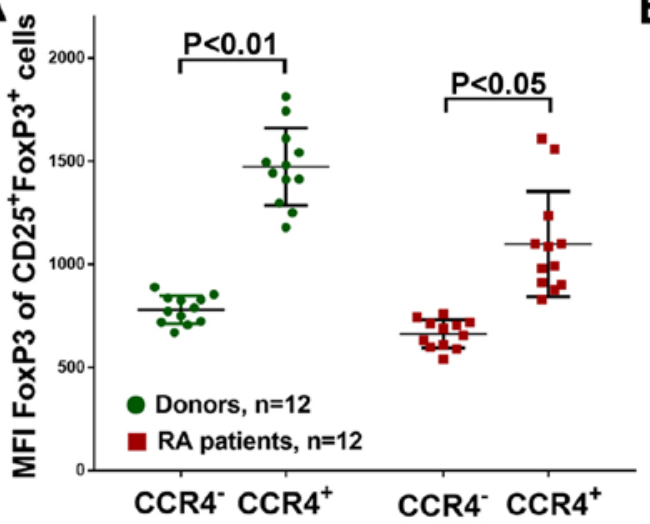

B

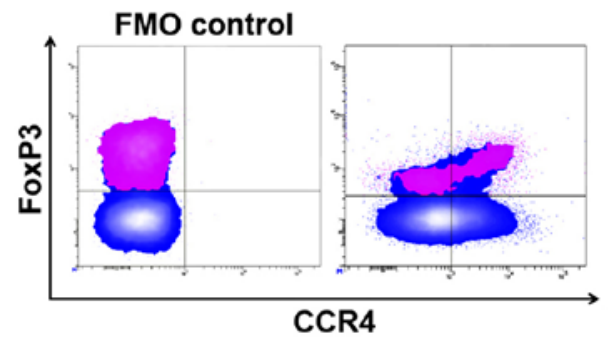

Figure 7. Evaluation of FoxP3 expression on Treg-cells in RA. (A) MFI of FoxP3 expression in CD25 ${ }^{+}$FoxP $3{ }^{+}$Treg cells, as a function of CCR4 expression in the peripheral blood from donors $(n=12)$ and patients with RA $(n=12)$. (B) Gating of CCR4 $4^{+}$Treg from CD25 ${ }^{+}$FoxP $3^{+}$lymphocytes in one patient with RA. The data are presented as the median and $25-75 \%$ interquartile range and analyzed using the Mann-Whitney test. Treg, regulatory T cells; MFI, mean fluorescence intensity; FMO, fluorescence minus one.
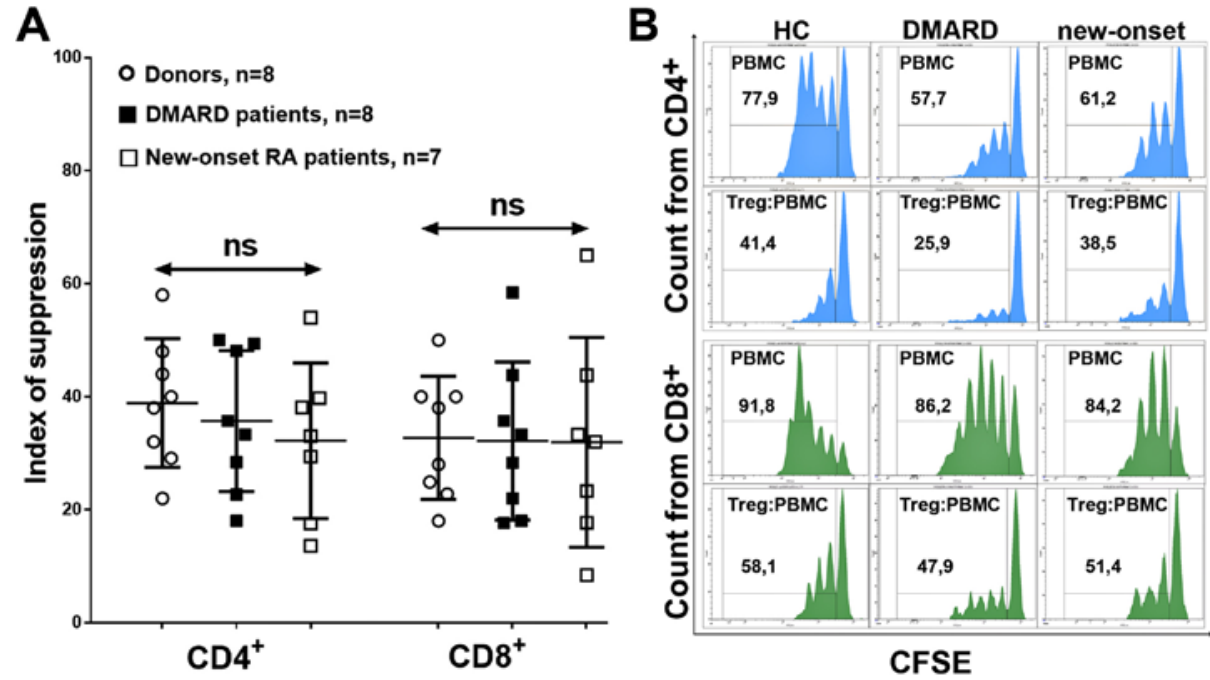

Figure 8. $\mathrm{CD}^{+}$and $\mathrm{CD}^{+}$suppression index calculation. (A) Treg CD4 ${ }^{+}$and $\mathrm{CD} 8^{+}$suppression index for the donors ( $\mathrm{n}=8$ ), and patients with new-onset $\mathrm{RA}$ ( $\mathrm{n}=7$ ) and receiving DMARD $(\mathrm{n}=8)$. (B) Gating for suppressor index calculation. The data are presented as the median and $25-75 \%$ interquartile range and analyzed using a Kruskal-Wallis test followed by Dunn's post hoc test. Treg, regulatory T cells; HC, healthy controls; DMARD, disease-modifying anti-rheumatic drugs; RA, rheumatoid arthritis; PMBC, peripheral blood mononuclear cells; CFSE, carboxyfluorescein succinimidyl ester; ns, not significant.

could be due to the higher CD86 ${ }^{+}$Treg concentrations and was possibly associated with the Treg activation in RA. To further investigate this issue, the HLA-DR activation marker expression on Treg lymphocytes was determined. The expression of this molecule was previously found to be associated with elevated FoxP3 expression (14). HLA-DR+Treg lymphocytes are activated inflammation-associated Treg cells predominant in inflammation foci in RA, and they can recirculate and emerge in peripheral blood. Such Treg cells have strong suppressive effects against effector lymphocytes $(13,33)$. The present study identified an increased $\mathrm{HLA}-\mathrm{DR}^{+}$Treg percentage in all patients with RA (Fig. 6B).

To investigate the migration of Treg cells, the expression of CCR4 was investigated. Patients with RA had a higher $\mathrm{CCR}^{+}{ }^{+}$Treg percentage (Fig. 6B), In addition, CCR4+Treg cells had a higher FoxP3 expression in either group, as determined by the mean of the FoxP3-PE channel fluorescence intensity (Fig. 7), which might also indicate the activation and greater functional activity of $\mathrm{CCR} 4^{+}$Treg in RA in addition to HLA-DR ${ }^{+}$Treg.

Thus, patients with RA had Treg cells with a lower CTLA-4 expression; however, they had higher PD-L1, CD86, HLA-DR and CCR4 expression.

Functional activity of Treg-cells in RA. To investigate the Treg functionality and the key mechanisms involved, the Treg ability to inhibit the proliferation of $\mathrm{CD}^{+}$and $\mathrm{CD} 8^{+}$lymphocytes, the TGF- $\beta$ and IL-10 concentrations in the supernatant, and the CTLA-4/PD-L1 expression on the Treg membrane were determined. Patients with RA were exactly matched to age- and sex-corresponded healthy donors for this analysis. In addition, in the Treg suppression assay, DMARD and new-onset RA patients were calculated as two separate groups.

Suppression of proliferation was determined using the suppressor index, which did not differ in donors or different groups of patients, which indicated preserved suppressor 


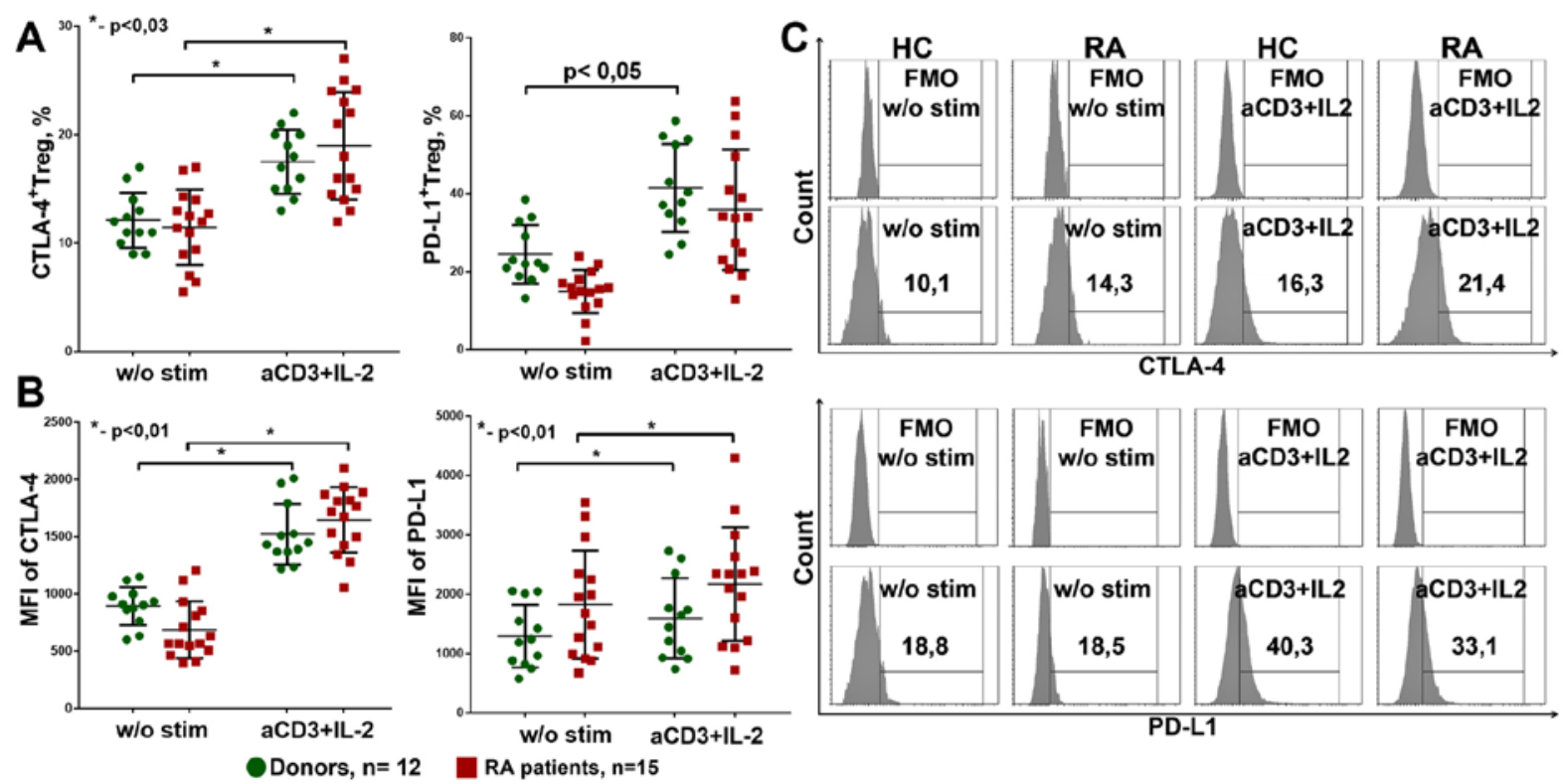

Figure 9. $\mathrm{CTLA}^{+}$and PD-L1 ${ }^{+}$expression on Treg. (A) $\mathrm{CTLA}^{+}{ }^{+}$and PD-L1+Treg percentage from culture. Healthy donors, $\mathrm{n}=12$, RA patients, $\mathrm{n}=15$. (B) MFI of CTLA-4 and PD-L1 expression on Treg in culture. Healthy donors, n=12, RA patients, $n=15$. (C) Gating strategy for CTLA-4 and PD-L1. The data are presented as the median and 25-75\% interquartile range, and was analyzed using the Mann-Whitney test for independent groups and with the Wilcoxon test for related groups. "P<0.01. w/o, without; a, anti; stim, stimulated; Treg, regulatory T cells; HC, healthy controls; RA, rheumatoid arthritis; MFI, mean fluorescence intensity; FMO, fluorescence minus one.
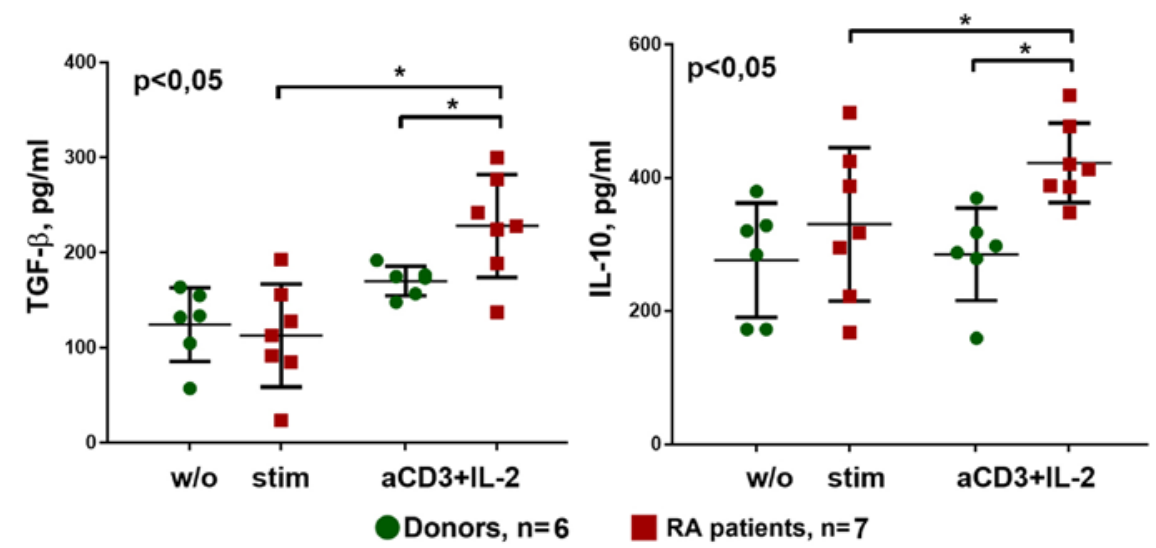

Figure 10. Secretion of cytokines during cultivation with anti-CD3 + IL-2 stimulation. Concentrations of IL-10 and TGF- $\beta$ in supernatant from co-culture of Treg and PBMCs. Healthy donors, $n=6$, RA patients, $n=7$. The data are presented as the median and $25-75 \%$ interquartile range and was analyzed using the Mann-Whitney test for independent groups and with the Wilcoxon test for related groups. "P<0.05. w/o, without; a, anti; stim, stimulated; Treg, regulatory T cells; RA, rheumatoid arthritis; PMBC, peripheral blood mononuclear cells.

activity of the general Treg cell pool in RA, with respect to both $\mathrm{CD} 4^{+}$and $\mathrm{CD} 8^{+}$(Fig. 8).

As the suppression activity of Treg cells did not differ between patients with RA and receiving DMARD therapy and patients with new-onset RA, the expression of CTLA-4/PD-L1 and the secretion of IL- 10 and TGF- $\beta$ were determined in a common group of patients. After 4 days of cultivation, surface CTLA-4 and PD-L1 expression did not differ between donors and patients (Fig. 9A). In addition, in donors and patients with RA, the percentage of CTLA- $4^{+}$Treg increased during stimulation. The percentage of PD-L1+Treg was significantly increased under anti-CD3+IL-2 stimulation only in donors.

The densities of CTLA-4 and PD-L1 expression on Treg cells also increased during stimulation with anti-CD3+IL-2 in both the patients with RA and the donor groups, but did not differ between these groups (Fig. 9B). Thus, anti-CD3+IL-2 stimulation could increase Treg suppressive ability by promoting PD-L1 and CTLA-4 expression.

With respect to the secretion of cytokines during cultivation with anti-CD3 + IL-2 stimulation, TGF- $\beta$ and IL-10 production was significantly higher in patients with RA compared with that in donors. In addition, anti-CD3+IL-2 stimulation increased secretion of these cytokines, particularly in the patient group (Fig. 10).

\section{Discussion}

Previous studies have revealed that autotolerance disorders are associated with autoimmune conditions, for example, RA develops from the imbalance of regulatory and effector 
mechanisms, and the imbalance itself was associated, not only with the excess activation of effectors, but also with defects in regulatory $\mathrm{T}$ cells (34-36). However, in the present study it was found that the Treg pool in patients with RA has the same quantitative and qualitative characteristics compared with that in the healthy donors. Namely, that the general Treg pool retains healthy suppressor activity, with respect to $\mathrm{CD} 4^{+}$and $\mathrm{CD}^{+}$lymphocytes. Furthermore, there were no significant associations between percentage of Treg and clinical parameters, such as ESR, CRP and RF (data not shown). This may be due to the preservation of Treg numbers in the peripheral blood in RA, which is consistent with the ROC analysis of Treg percentage.

Stimulation with anti-CD3+IL-2 promoted PD-L1 and CTLA-4 expression on Treg cells in healthy donors and RA patients since IL-2 is one of the most important cytokines for Treg cell homeostasis, which, when combined with a strong signal using TCR, by anti-CD3 stimulation, can lead to activation and increasing suppressor capacity of Treg cells (3).

In addition, the cultures of RA patients had higher IL-10 and TGF- $\beta$ production levels, under anti-CD3+IL-2 stimulation, which is a sign of increased Treg activation. It can be hypothesized that regulatory $\mathrm{T}$ cells require activation to maintain the immunity balance in RA, i.e. to compensate for the excess activation of effector cells. This hypothesis was supported by the raised concentrations of $\mathrm{CCR} 4^{+}$-a chemokine receptor that enables homing to inflammation foci, and HLA-DR ${ }^{+}$Treg cells with higher FoxP3 expression, as well as by the elevated expression of PD-L1 in patients with RA-a finding consistent with previous studies (37-39). Lower CTLA-4 expression on the surface of Tregs in RA has been hypothesized to be associated with a reduction in suppressor activity $(40,41)$; however, it might also indicate a greater Treg involvement in contact with APCs. CTLA-4 molecules are constitutively expressed by Treg cells intracellularly, near the membrane in vesicles (42). These vesicles merge with the membrane from time to time, which causes CTLA-4 molecules to emerge on the lymphocyte surface. Such recirculation of CTLA-4 is amplified when stimulating Treg TCRs by interacting with the peptide part of MHC-II on APCs (43). Thus, when a Treg contacts APCs, surface CTLA-4 molecules bind to CD80/86 co-stimulation molecules and disrupt antigen presentation (44). Then, a segment of the membrane near the CTLA-4-CD80/86 complex submerges into the Treg and recreates the vesicles, which merge with lysosomes, causing co-stimulation molecules to degrade. However, not all B7 molecules undergo lysis as some might emerge on the Treg surface (15). This leads to the hypothesis that lower CTLA-4 expression on Treg cells, as well as a greater $\mathrm{CD} 86^{+}$Treg concentration in RA, may be due to these cells being more active and involved in contact suppression with APCs. With respect to the CTLA-4/CD86 interaction during strong TCR signaling, which leads to an increase in trans-endocytosis, that may suggest that Treg lymphocytes are involved in contacting APC to a greater extent in RA compared with that in healthy individuals (15). Apparently, clones with a high affinity to self-antigens better represent in the $\mathrm{CD}^{+} 6^{+}$Treg subset. However, this assumption requires further investigation. Therefore, it can be hypothesized that the expression of B7 molecules on the Treg surface demonstrates the higher functional activity of some antigen-specific clones of Tregs; however subsequent effects of this expression are understudied and require additional research.

The increased activation and persistent suppressor activity of Treg cells in RA indicated that cells had adapted to chronic inflammation; however, RA still disrupted the immune balance. Earlier study proved that Treg cells were unable to effectively suppress $\mathrm{CD} 161^{+} \mathrm{Th}$ proliferation, while still being able to suppress the proliferation of other CD161 Th lymphocytes (16). CD161 ${ }^{+} \mathrm{Th}$ lymphocytes are a pool of CD4 ${ }^{+} \mathrm{RORyt}^{+}$ cells producing IL-17A, IL-17F, IL-22, TNF $\alpha$ and other pro-inflammatory factors $(45,46)$. This leads to the assumption that it is not a lower suppressor activity of the general Treg pool that disrupts the immune balance in RA; rather, it is the insufficient suppressor activity against specific CD161 ${ }^{+} \mathrm{RORyt}^{+}$ lymphocytes, the peripheral-blood and synovial concentration, which rises in RA $(17,47)$. The present study also showed that patients with RA had more FoxP $3^{+} \mathrm{RORyt}^{+}$and $\mathrm{CD} 4^{+} \mathrm{RORyt}^{+}$ cells, and their percentage was highly correlated with disease activity; however, these cells are still only a small part of the Th pool and could not have significantly affected the Treg suppressor activity estimates. It is worth noting that IL-17 expression determined using flow cytometry requires previous stimulation and may not reflect the initial expression of IL-17 in lymphocytes from PBMCs $(48,49)$. Therefore, the transcription factor, RORyt, was used as a marker of differentiation for Th-17 cells, which reflects the initial stage of transition when the IL-17 expression may not be detected $(19,29)$.

Another immune imbalance mechanism triggered by RA is the effector resistance to Treg suppression in inflammation. The resistance to Treg-issued inhibitory signals has been shown to be unrelated to APC activation or the effector cell memory phenotype; rather, it depends on the activation of protein kinase $\mathrm{B}(\mathrm{PKB}) / \mathrm{c}$-akt in effector cells exposed to TNF $\alpha$ and IL-6 at inflammation sites (50). Inhibiting this kinase restores the effector cell response to Treg suppression. Another study showed that when removed from the inflammatory environment, Tregs effectively suppressed the production of proinflammatory cytokines and the proliferation of effector T cells (51). Taken together, the general Treg pool does not lose its function in RA.

Balancing effector and regulatory immunity are active processes where multiple mechanisms are involved to attain a dynamic balance (3). This may be why the general Treg pool retains its suppressor activity in RA, while Treg cells have an activated phenotype due to greater tension imposed on the regulatory mechanisms in chronic inflammation (33). Evidently, the inflammatory microenvironment causes some Treg cells to continuously convert into pathogenic exFoxP3-Th-17 lymphocytes (17), that resist Treg inhibition and cause self-sustained inflammation (16). Rossetti et al (33) found that some activated Treg cells, pertaining to synovial inflammation, share the TCR antigenic specificity with effector $\mathrm{T}$ lymphocytes involved in sustaining articular inflammation; these Treg cells express HLA-DR. This means that Treg cells have some antigen-specific effects. It therefore seems important to consider, not only the Treg subpopulation in terms of the expression of different molecules, but also the heterogeneity of this population, as determined by the antigen specificity of TCRs. Perhaps the regulatory defects in RA are not population-wide, but pertain to a limited set of Treg clones 
highly specific to particular antigens, the tolerance to which has been compromised $(3,52)$.

In conclusion, intolerance to body-produced antigens in RA could be due to excessive activation of effector cells, as well as defects in regulatory $\mathrm{T}$ cells $(1,11)$. The present study showed that Treg cells were activated in RA and retained suppressor activity against $\mathrm{CD}^{+}$and $\mathrm{CD}^{+}$in both patients with new-onset RA and those receiving DMARD treatment. Transitional FoxP $3{ }^{+} \mathrm{RORyt}^{+}$forms and increased CD4 ${ }^{+} \mathrm{RORyt}^{+}$ concentrations indicated the pathological propensity of Treg cells to convert into Th17 in RA, which could to be the most important factor of sustaining a chronic autoimmune process, particularly in light of a previous report that the inability of Treg cells to effectively suppress exFoxP3-Th17 proliferation and proinflammatory cytokine production (16).

\section{Acknowledgements}

Not Applicable.

\section{Funding}

RFBR and Novosibirsk Region funded this work according to the research project № 17-44-540167

\section{Availability of data and materials}

The datasets used and/or analyzed during the current study are available from the corresponding author on reasonable request.

\section{Authors' contributions}

DS performed experimental work, contributed to the conception, drafting of the manuscript, and design. VT contributed to the conception and revision of the manuscript. VK contributed to the final approval of the manuscript. AS, OS, and VK contributed to patients recruitment and clinical evaluation of parameters of RA patients. All authors read and approved the final manuscript.

\section{Ethics approval and consent to participate}

This study was approved by the Local Ethics Committee's Approval (protocol no. 110: October 11, 2018; RIFCI Ethics Committee).

\section{Patient consent for publication}

Not Applicable.

\section{Competing interests}

The authors declare that they have no competing interests.

\section{References}

1. Smolen JS, Aletaha D, Barton A, Burmester GR, Emery P, Firestein GS, Kavanaugh A, McInnes IB, Solomon DH, Strand V and Yamamoto K: Rheumatoid arthritis. Nat Rev Dis Primers 4: $18001,2018$.
2. Fang Q, Zhou C and Nandakumar KS: Molecular and cellular pathways contributing to joint damage in rheumatoid arthritis. Mediators Inflamm 2020: 3830212, 2020.

3. Shevyrev D and Tereshchenko V: Treg heterogeneity, function, and homeostasis. Front Immunol 10: 3100, 2020.

4. Ehrenstein MR, Evans JG, Singh A, Moore S, Warnes G, Isenberg DA and Mauri C: Compromised function of regulatory $\mathrm{T}$ cells in rheumatoid arthritis and reversal by anti-TNFalpha therapy. J Exp Med 200: 277-285, 2004.

5. Morita T, Shima Y, Wing JB, Sakaguchi S, Ogata A and Kumanogoh A: The proportion of regulatory $\mathrm{T}$ cells in patients with rheumatoid arthritis: A Meta-analysis. PLoS One 11: e0162306, 2016.

6. Zhang X, Zhang X, Zhuang L, Xu C, Li T, Zhang G and Liu Y: Decreased regulatory $\mathrm{T}$-cell frequency and interleukin-35 levels in patients with rheumatoid arthritis. Exp Ther Med 16: 5366-5372, 2018.

7. Abazaa N, EL-kabarityb RH and Abo-Shadyb RA: Deficient or abundant but unable to fight? Estimation of circulating FoxP3+ $\mathrm{T}$ regulatory cells and their counteracting FoxP3-in rheumatoid arthritis and correlation with disease activity. Egypt Rheum 35: 185-192, 2013.

8. Walter GJ, Evans HG, Menon B, Gullick NJ, Kirkham BW, Cope AP, Geissmann F and Taams LS: Interaction with activated monocytes enhances cytokine expression and suppressive activity of human $\mathrm{CD} 4{ }^{+} \mathrm{CD} 45 \mathrm{ro}^{+} \mathrm{CD} 25^{+} \mathrm{CD} 127^{\text {low }}$ regulatory $\mathrm{T}$ cells. Arthritis Rheum 65: 627-638, 2013.

9. Kanjana K, Paisooksantivatana K, Matangkasombut P, Chevaisrakul P and Lumjiaktase P: Efficient short-term expansion of human peripheral blood regulatory $\mathrm{T}$ cells for co-culture suppression assay. J Immunoassay Immunochem 40: 573-589, 2019.

10. Walter GJ, Fleskens V, Frederiksen KS, Rajasekhar M, Menon B Gerwien JG, Evans HG and Taams LS: Phenotypic, functional, and gene expression profiling of peripheral $\mathrm{CD}_{45 \mathrm{RA}^{+}}$and $\mathrm{CD} 45 \mathrm{RO}^{+} \mathrm{CD} 4{ }^{+} \mathrm{CD} 25^{+} \mathrm{CD} 127^{\text {low }}$ treg cells in patients with chronic rheumatoid arthritis. Arthritis Rheumatol 68: 103-116, 2016.

11. Nie H, Zheng Y, Li R, Guo TB, He D, Fang L, Liu X, Xiao L, Chen X, Wan B, et al: Phosphorylation of FOXP3 controls regulatory $\mathrm{T}$ cell function and is inhibited by TNF- $\alpha$ in rheumatoid arthritis. Nat Med 19: 322-328, 2013.

12. Zhang N, Schröppel B, Lal G, Jakubzick C, Mao X, Chen D, Yin N, Jessberger R, Ochando JC, Ding Y and Bromberg JS: Regulatory $\mathrm{T}$ cells sequentially migrate from inflamed tissues to draining lymph nodes to suppress the alloimmune response. Immunity 30: 458-469, 2009.

13. Baecher-Allan C, Wolf E and Hafler DA: MHC class II expression identifies functionally distinct human regulatory $\mathrm{T}$ cells. J Immunol 176: 4622-4631, 2006.

14. Shevyrev DV, Blinova EA and Kozlov VA: The influence of humoral factors of homeostatic proliferation on t-regulatory cells in vitro. Bull Siberian Med 18: 286-293, 2019.

15. Qureshi OS, Zheng Y, Nakamura K, Attridge K, Manzotti C, Schmidt EM, Baker J, Jeffery LE, Kaur S, Briggs Z, et al: Trans-endocytosis of CD80 and CD86: A molecular basis for the cell-extrinsic function of CTLA-4. Science 332: 600-603, 2011.

16. Basdeo SA, Moran B, Cluxton D, Canavan M, McCormick J, Connolly M, Orr C, Mills KH, Veale DJ, Fearon U and Fletcher JM: Polyfunctional, pathogenic CD161 ${ }^{+}$Th17 lineage cells are resistant to regulatory $\mathrm{T}$ cell-mediated suppression in the context of autoimmunity. J Immunol 195: 528-540, 2015.

17. Komatsu N, Okamoto K, Sawa S, Nakashima T, Oh-hora M, Kodama T, Tanaka S, Bluestone JA and Takayanagi H: Pathogenic conversion of Foxp3+ T-cells into TH17 cells in autoimmune arthritis. Nat Med 20: 62-70, 2014.

18. Korn T, Bettelli E, Oukka M and Kuchroo VK: IL-17 and Th17 cells. Annu Rev Immunol 27: 485-517, 2009.

19. Ivanov II, McKenzie BS, Zhou L, Tadokoro CE, Lepelley A, Lafaille JJ, Cua DJ and Littman DR: The orphan nuclear receptor ROR $\gamma \mathrm{t}$ directs the differentiation program of proinflammatory IL-1 $7^{+}$T helper cells. Cell 126: 1121-1133, 2006.

20. Aletaha D, Ward MM, Machold KP, Nell VP, Stamm T and Smolen JS: Remission and active disease in rheumatoid arthritis: Defining criteria for disease activity states. Arthritis Rheum 52: 2625-2636, 2005.

21. van der Heijde DM, van't Hof M, van Riel PL and van de Putte LB: Development of a disease activity score based on judgment in clinical practice by rheumatologists. J Rheumatol 20: 579-581, 1993. 
22. Scott PJ and Huskisson EC: Measurement of functional capacity with visual analogue scales. Rheumatol Rehabil 16: 257-259, 1977.

23. Aletaha D, Neogi T, Silman AJ, Funovits J, Felson DT, Bingham CO III, Birnbaum NS, Burmester GR, Bykerk VP, Cohen MD, et al: 2010 Rheumatoid arthritis classification criteria: An American College of Rheumatology/European League Against Rheumatism collaborative initiative. Arthritis Rheum 62: 2569-2581, 2010.

24. Böyum A: Isolation of leucocytes from human blood. Further observations. Methylcellulose, dextran, and ficoll as erythrocyteaggregating agents. Scand J Clin Lab Invest Suppl 97: 31-50, 1968.

25. Böyum A: Isolation of mononuclear cells and granulocytes from human blood. Isolation of monuclear cells by one centrifugation, and of granulocytes by combining centrifugation and sedimentation at 1 g. Scand J Clin Lab Invest Suppl 97: 77-89, 1968.

26. Collison LW and Vignali DA: In vitro Treg suppression assays. Methods Mol Biol 707: 21-37, 2011.

27. Mahmud SA, Manlove LS and Farrar MA: Interleukin-2 and STAT5 in regulatory $\mathrm{T}$ cell development and function. JAKSTAT 2: e23154, 2013.

28. Hua J, Inomata T, Chen Y, Foulsham W, Stevenson W, Shiang T, Bluestone JA and Dana R: Pathological conversion of regulatory $\mathrm{T}$ cells is associated with loss of allotolerance. Sci Rep 8: 7059 , 2018.

29. Ivanov II, Zhou L and Littman DR: Transcriptional regulation of Th17 cell differentiation. Semin Immunol 19: 409-417, 2007.

30. Tada Y, Ono N, Suematsu R, Tashiro S, Sadanaga Y, Tokuda Y, Ono Y, Nakao Y, Maruyama A, Ohta A and Koarada S: The balance between Foxp3 and Ror- $\gamma$ t expression in peripheral blood is altered by tocilizumab and abatacept in patients with rheumatoid arthritis. BMC Musculoskelet Disord 17: 290, 2016.

31. Kugyelka R, Kohl Z, Olasz K, Mikecz K, Rauch TA, Glant TT and Boldizsar F: Enigma of IL-17 and Th17 cells in rheumatoid arthritis and in autoimmune animal models of arthritis. Mediators Inflamm 2016: 6145810, 2016.

32. Kim BS, Lu H, Ichiyama K, Chen X, Zhang YB, Mistry NA, Tanaka K, Lee YH, Nurieva R, Zhang L, et al: Generation of ROR $\gamma \mathrm{t}^{+}$Antigen-Specific T regulatory 17 cells from Foxp ${ }^{+}$ precursors in autoimmunity. Cell Rep 21: 195-207, 2017.

33. Rossetti M, Spreafico R, Consolaro A, Leong JY, Chua C, Massa M, Saidin S, Magni-Manzoni S, Arkachaisri T, Wallace CA, et al: TCR repertoire sequencing identifies synovial Treg cell clonotypes in the bloodstream during active inflammation in human arthritis. Ann Rheum Dis 76: 435-441, 2017.

34. Dejaco C, Duftner C, Grubeck-Loebenstein B and Schirmer M Imbalance of regulatory $\mathrm{T}$ cells in human autoimmune diseases. Immunology 117: 289-300, 2006.

35. Lee GR: The Balance of Th17 versus Treg cells in autoimmunity Int J Mol Sci 19: 730, 2018

36. Horwitz DA, Fahmy TM, Piccirillo CA and La Cava A: Rebalancing immune homeostasis to treat autoimmune diseases. Trends Immunol 40: 888-908, 2019.

37. Shalini PU, Debnath T, Jvs V, Kona LK, Kamaraju SR, Kancherla R and Chelluri LK: A study on FoxP3 and Tregs in paired samples of peripheral blood and synovium in rheumatoid arthritis. Cent Eur J Immunol 40: 431-436, 2015.

38. Li N, Wei W, Yin F, Chen M, Ma TR, Wu Q, Zhou JR, Zheng SG and Han J: The abnormal expression of CCR4 and CCR6 on Tregs in rheumatoid arthritis. Int J Clin Exp Med 8: 15043-15053, 2015.
39. Al-Banna NA, Vaci M, Slauenwhite D, Johnston B and Issekutz TB: CCR4 and CXCR3 play different roles in the migration of T cells to inflammation in skin, arthritic joints, and lymph nodes. Eur J Immunol 44: 1633-1643, 2014.

40. Cribbs AP, Kennedy A, Penn H, Read JE, Amjadi P, Green P, Syed K, Manka SW, Brennan FM, Gregory B and Williams RO: Treg cell function in rheumatoid arthritis is compromised by ctla-4 promoter methylation resulting in a failure to activate the indoleamine 2,3-dioxygenase pathway. Arthritis Rheumatol 66: 2344-2354, 2014.

41. Flores-Borja F, Jury EC, Mauri C and Ehrenstein MR: Defects in CTLA-4 are associated with abnormal regulatory $\mathrm{T}$ cell function in rheumatoid arthritis. Proc Natl Acad Sci USA 105: 19396-19401, 2008

42. Walker LS: Treg and CTLA-4: Two intertwining pathways to immune tolerance. J Autoimmun 45: 49-57, 2013.

43. Linsley PS, Bradshaw J, Greene J, Peach R, Bennett KL and Mittler RS: Intracellular trafficking of CTLA-4 and focal localization towards sites of TCR engagement. Immunity 4: 535-543, 1996.

44. Sansom DM: CD28, CTLA-4 and their ligands: Who does what and to whom? Immunology 101: 169-177, 2000.

45. Pesenacker AM, Bending D, Ursu S, Wu Q, Nistala K and Wedderburn LR: CD161 defines the subset of FoxP3 ${ }^{+} \mathrm{T}$ cells capable of producing proinflammatory cytokines. Blood 121: 2647-2658, 2013

46. Afzali B, Mitchell PJ, Edozie FC, Povoleri GA, Dowson SE, Demandt L, Walter G, Canavan JB, Scotta C, Menon B, et al: CD161 expression characterizes a subpopulation of human regulatory T cells that produces IL-17 in a STAT3-dependent manner. Eur J Immunol 43: 2043-2054, 2013.

47. Sato K, Suematsu A, Okamoto K, Yamaguchi A, Morishita Y, Kadono Y, Tanaka S, Kodama T, Akira S, Iwakura Y, et al: Th17 functions as an osteoclastogenic helper T cell subset that links T cell activation and bone destruction. J Exp Med 203: 2673-2682, 2006.

48. Pappu BPand Dong C: Measurement of interleukin-17.CurrProtoc Immunol: Chapter 6:Unit 6.25, 2007. doi:10.1002/0471142735. im0625s 79 .

49. Zhao L, Chou Y, Jiang Y, Jiang Z and Chu CQ: Analysis of IL-17 production by flow cytometry and ELISPOT assays. Methods Mol Biol 1172: 243-256, 2014.

50. Wehrens EJ, Mijnheer G, Duurland CL, Klein M, Meerding J, van Loosdregt J, de Jager W, Sawitzki B, Coffer PJ, Vastert B, et al: Functional human regulatory $\mathrm{T}$ cells fail to control autoimmune inflammation due to PKB/c-Akt hyperactivation in effector cells. Blood 118: 3538-3548, 2011.

51. Herrath J, Müller M, Amoudruz P, Janson P, Michaëlsson J, Larsson PT, Trollmo C, Raghavan S and Malmström V: The inflammatory milieu in the rheumatic joint reduces regulatory T-cell function. Eur J Immunol 41: 2279-2290, 2011.

52. Zemmour D, Zilionis R, Kiner E, Klein AM, Mathis D and Benoist C: Single-cell gene expression reveals a landscape of regulatory $\mathrm{T}$ cell phenotypes shaped by the TCR. Nat Immunol 19: 291-301, 2018.

This work is licensed under a Creative Commons Attribution-NonCommercial-NoDerivatives 4.0 International (CC BY-NC-ND 4.0) License. 